\title{
Phototriggered Base Amplification for Thiol-Michael Addition Reactions in Crosslinked Photopolymerizations with Efficient Dark Cure
}

Jasmine Sinha, ${ }^{1}$ Maciej Podgórski ${ }^{1,2}$ Andrew Tomaschke, ${ }^{3}$ Virginia L. Ferguson, ${ }^{3}$ and Christopher N. Bowman ${ }^{* 1}$

${ }^{1}$ Department of Chemical and Biological Engineering, University of Colorado Boulder, CO-80303, United States. ${ }^{2}$ Department of Polymer Chemistry, Faculty of Chemistry, Maria Curie-Sklodowska University, Gliniana St. 33, 20 614 Lublin, Poland.

${ }^{3}$ Department of Mechanical Engineering, University of Colorado Boulder, CO-80309, United States.

\section{Supplementary Information}

\section{Contents}

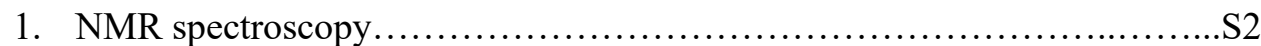

2. Synthesis of Base Amplifier..........................................S2

3. Reaction kinetics for model reaction, HA/BMP ............................S3

4. Reaction kinetics for model reaction, BMP/DVS .........................S3

5. Stability test for EVS-BMP............................................. 4

6. Reaction Kinetics of DVS-PETMP ..................................... 5

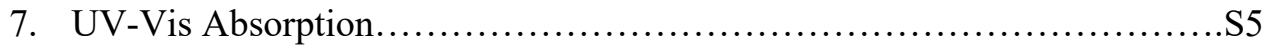

8. Storage Modulus..................................................... S6

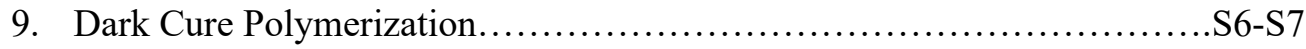

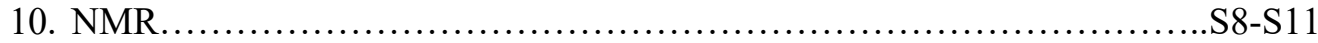




\section{NMR Spectroscopy}

${ }^{1} \mathrm{H}-\mathrm{NMR}$ and ${ }^{13} \mathrm{C}-\mathrm{NMR}$ spectra were recorded on a Bruker $400 \mathrm{MHz}$ NMR spectrometer. Proton chemical shifts are expressed in parts per million $(\delta)$ using TMS as an internal standard. The $\delta$ scale was referenced to deuterated solvents, indicated in the respective measurement.

\section{Synthesis of Base Amplifier}

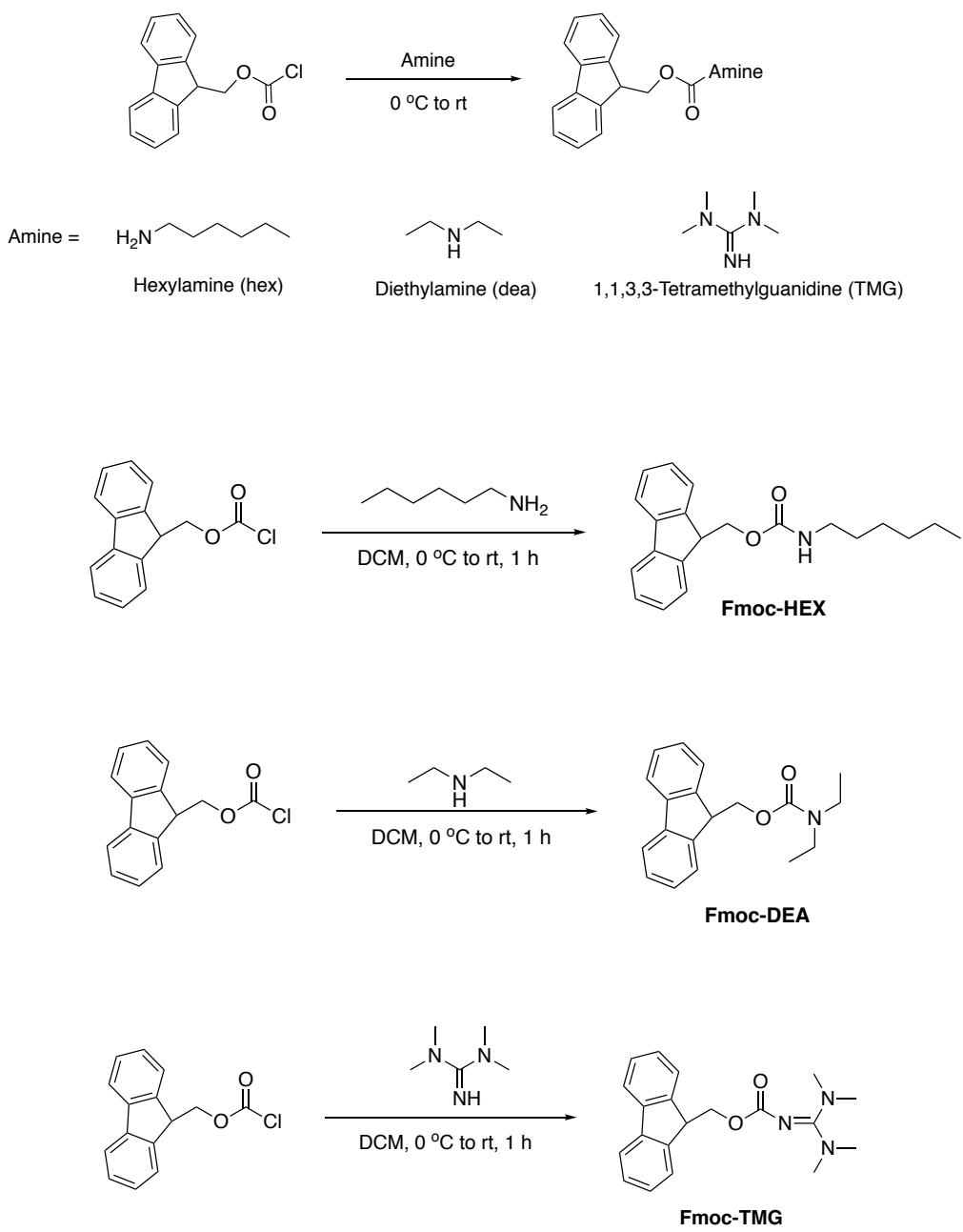




\section{Reaction kinetics for HA/BMP}

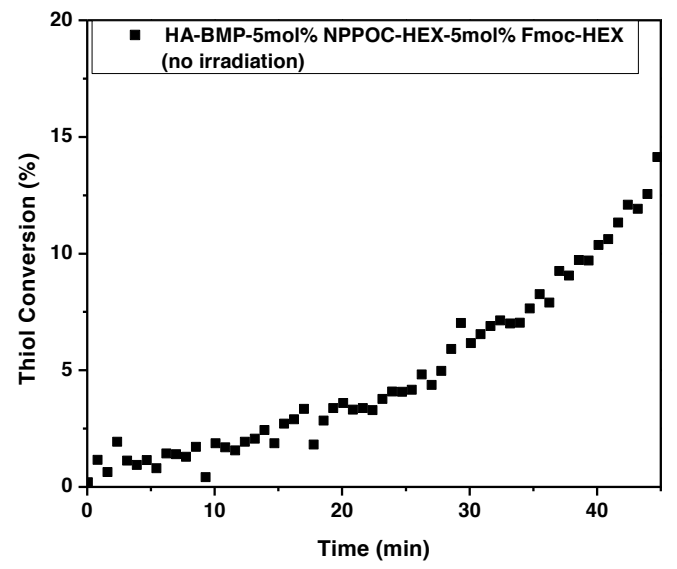

Fig S1. Thiol conversion versus time monitored by FT-IR for the model reaction between butyl 3-mercaptopropionate (BMP) and hexyl acrylate (HA) in presence of $5 \mathrm{~mol} \%$ NPPOC-HEX (photo caged amine) and $5 \mathrm{~mol} \%$ of Fmoc-HEX (base amplifier) at ambient temperature without irradiation (as control experiment). The mixture consists of initial stoichiometric ratio of $1: 1$ of thiol to vinyl functional group concentration.

\section{Reaction kinetics for model reaction, BMP/EVS}

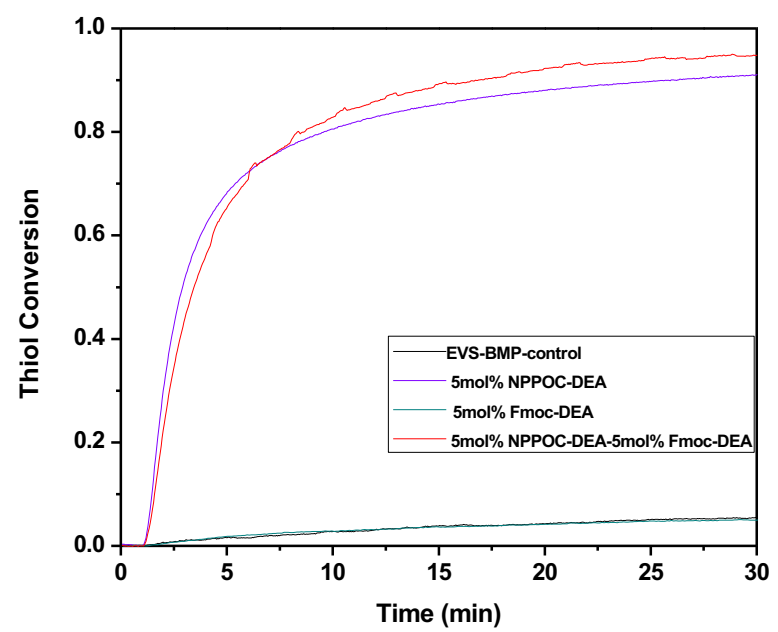

Fig S2. Thiol conversion versus time monitored by FT-IR for the model reaction between butyl 3-mercaptopropionate (BMP) and ethyl vinyl sulfone (EVS) in presence of $5 \mathrm{~mol} \%$ NPPOC-DEA (photo caged amine) and $5 \mathrm{~mol} \%$ of FmocDEA (base amplifier). The mixture consists of initial stoichiometric ratio of $1: 1$ of thiol to vinyl functional group concentration. Each sample was stabilized in dark for $1 \mathrm{~min}$ and then irradiated with $50 \mathrm{~mW} / \mathrm{cm}^{2} 365 \mathrm{~nm}$ wavelength at ambient temperature. 


\section{Stability test for EVS-BMP}

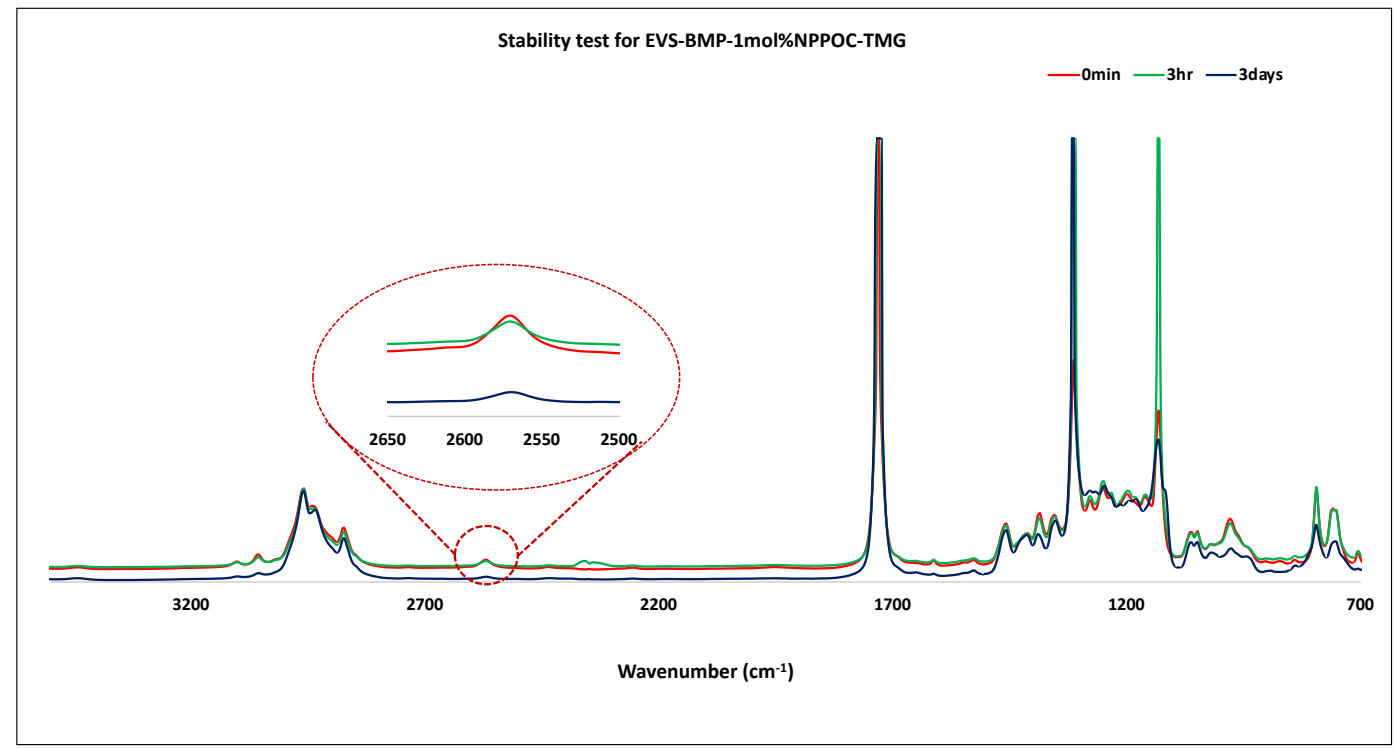

Fig S3. FTIR spectra of EVS and BMP in presence of $1 \mathrm{~mol} \%$ NPPOC-TMG at different time $0 \mathrm{~min}, 3 \mathrm{hr}$ and 3 days. The mixture with photobase was stored in dark after every measurement. The mixture consists of an initial stoichiometric ratio of 1:1 thiol to vinyl functional group concentration. The functional group conversion of each system was calculated from the peak area of the functional group $\left(2550-2600 \mathrm{~cm}^{-1}\right.$ for thiol).

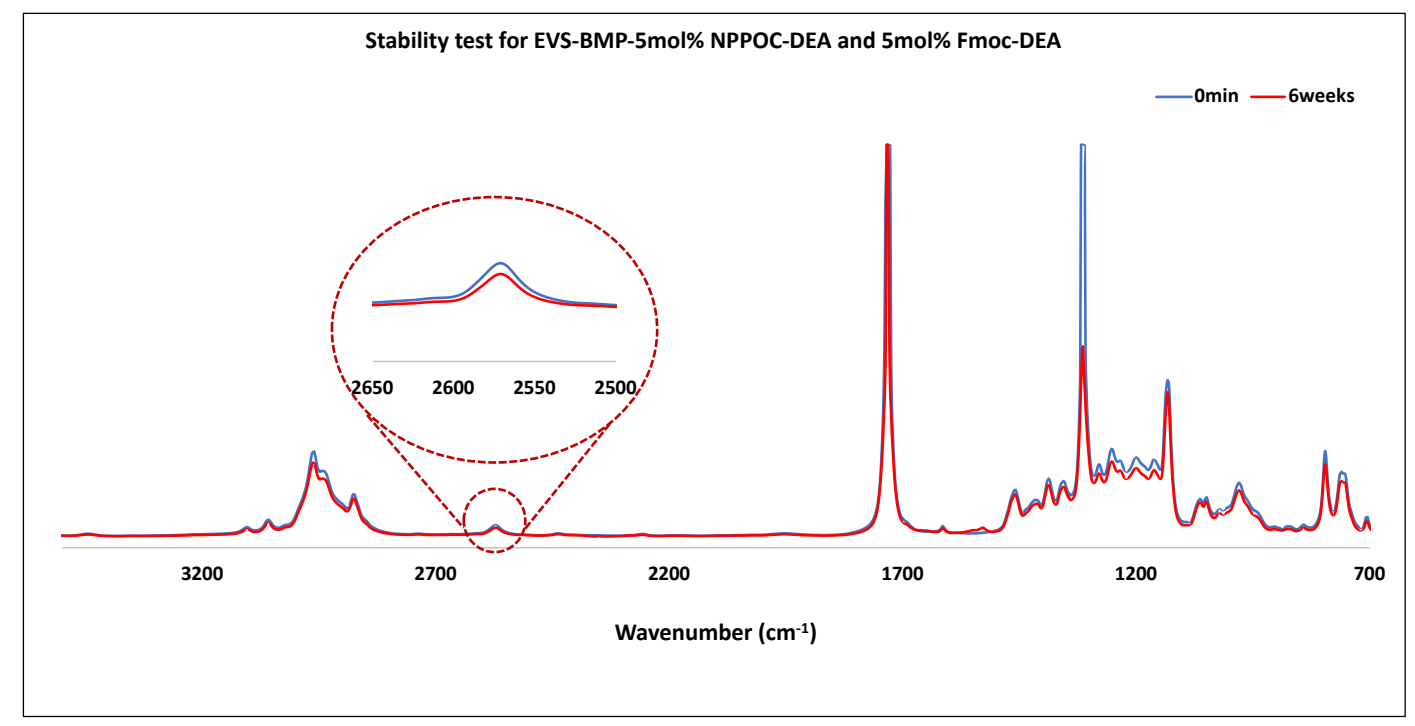

Fig S4. FTIR spectra of EVS and BMP in presence of 5mol $\%$ NPPOC-DEA and 5mol\% Fmoc-DEA at 0 min, and 6 weeks. The mixture with photobase was stored in dark after every measurement. The mixture consists of an initial stoichiometric ratio of 1:1 thiol to vinyl functional group concentration. The functional group conversion of each system was calculated from the peak area of the functional group $\left(2550-2600 \mathrm{~cm}^{-1}\right.$ for thiol). 


\section{Reaction Kinetics of DVS-PETMP}

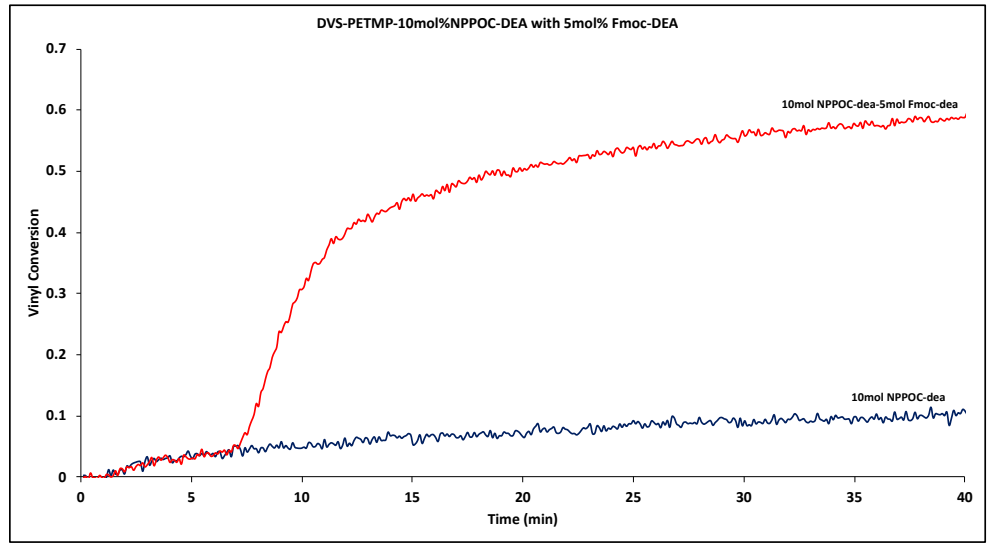

Fig S5. Vinyl conversion versus time as monitored by FT-IR for the network polymerization of DVS and PETMP in the presence of $10 \mathrm{~mol} \%$ NPPOC-DEA and in the presence of both $10 \mathrm{~mol} \%$ NPPOC-DEA and 5 mol\% Fmoc-DEA. The mixture consists of an initial stoichiometric ratio of 1:1 thiol to vinyl functional group concentration. Each sample was stabilized in the dark for $1 \mathrm{~min}$ and then irradiated with $50 \mathrm{~mW} / \mathrm{cm}^{2} 365 \mathrm{~nm}$ wavelength at ambient temperature.

\section{UV-Vis absorption}

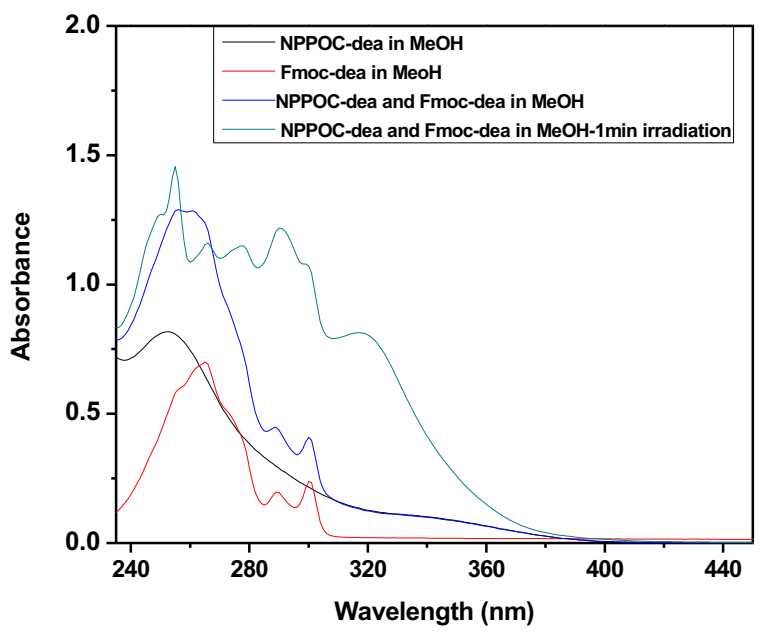

Fig S6. UV-Vis absorption evaluation of NPPOC-DEA, Fmoc-DEA, NPPOC-DEA ( $1 \mathrm{mM})$ and Fmoc-DEA $(0.15 \mathrm{mM})$ in methanol. UV-Vis absorption of NPPOC-DEA and Fmoc-DEA in methanol upon irradiation with $50 \mathrm{~mW} / \mathrm{cm}^{2}, 365$ nm light. 


\section{DMA}

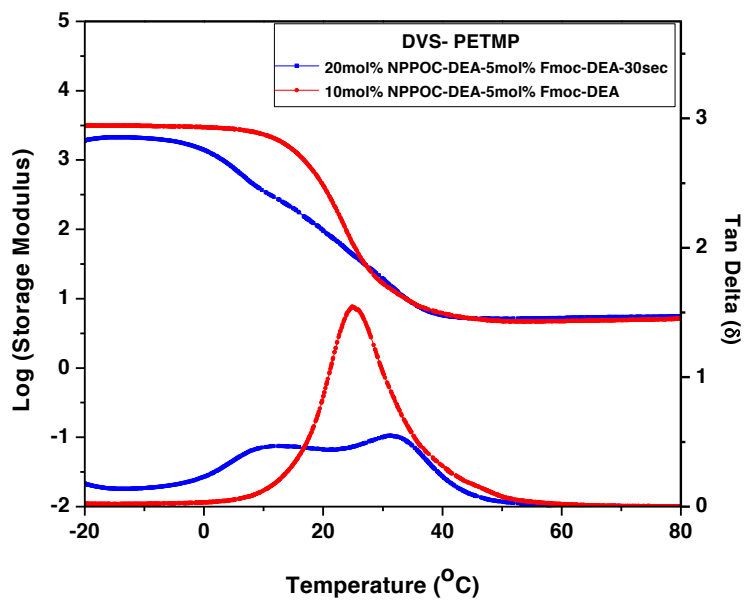

Fig S7. Storage Modulus profile for Crosslinked polymeric film made of DVS and PETMP catalyzed by 20 mol\% NPPOC-DEA, 20mol\% NPPOC-DEA in presence of $1 \mathrm{~mol} \%$ Fmoc-TMG or 5 mol\% Fmoc-DEA (continuous irradiation and dark cured sample) and $10 \mathrm{~mol} \%$ NPPOC-DEA in presence of 5mol\% Fmoc-DEA. FC in parentheses stands for functional group conversion.

\section{Dark Cure Polymerization}

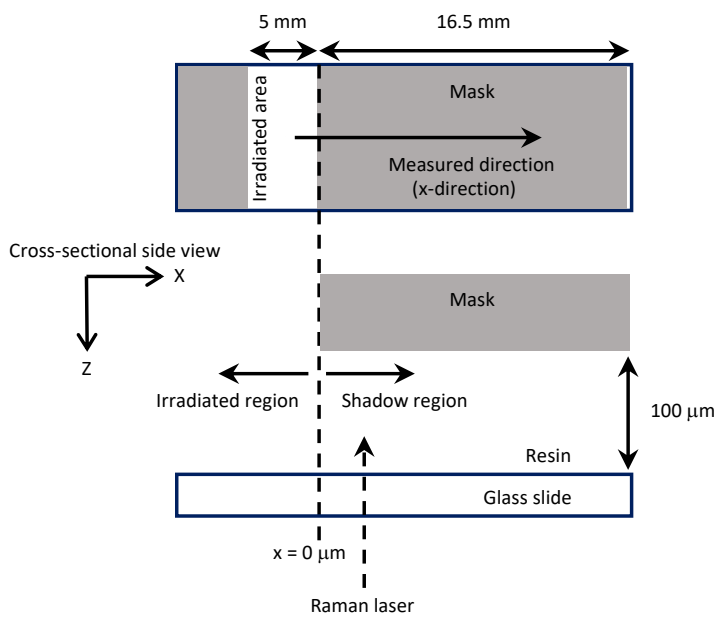

Fig S8. Schematic of the experimental geometry for the dark cure studies. Black tape was used to mask one side of the glass slide with a $5 \mathrm{~mm}$ width gap (untaped) through which TMPTA/PETMP monomer mixture were photopolymerization by photobase (NPPOC derivatives) and Base amplifier (Fmoc derivatives) and was illuminated using a mercury-lamp (Acticure 4000) with a $365 \mathrm{~nm}$ bandgap filter at $50 \mathrm{~mW} / \mathrm{cm}^{2}$ light intensity for $10 \mathrm{~min}$. After the illumination of the prescribed duration, black tape was removed, and Raman microscopy was used to collect line ( $x$-direction) and depth ( $z$-direction) conversion profile through the glass slide. 


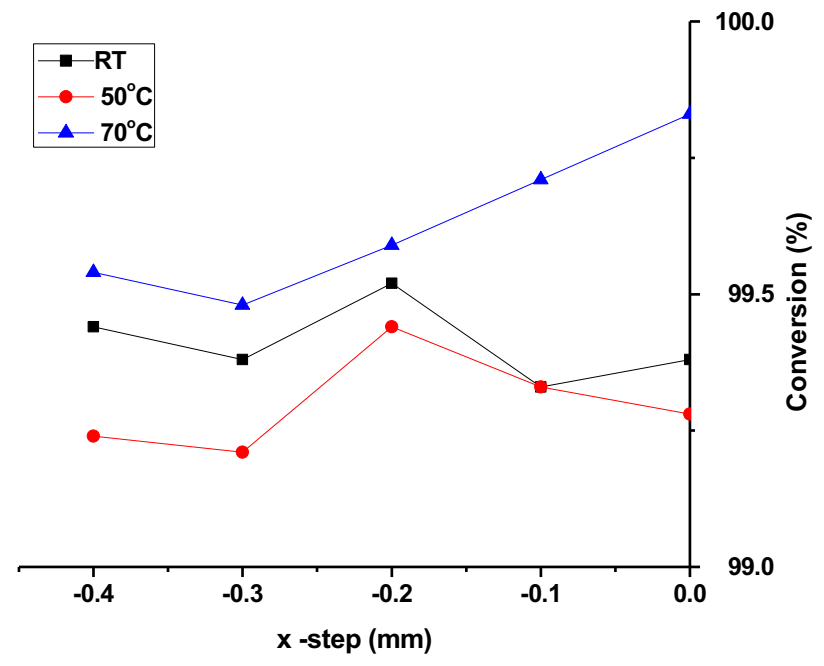

Fig S9. Dark Cure conversion profiles for negative values of $x$ correspond to the illuminated region ( $x$-direction) resulting from three different temperature $\left(\mathrm{RT}, 50^{\circ} \mathrm{C}\right.$ and $\left.70^{\circ} \mathrm{C}\right)$ for TMPTA/PETMP in presence of $20 \mathrm{~mol} \%$ NPPOCDEA and $1 \mathrm{~mol} \%$ Fmoc-TMG. Irradiated using a Hg source with $365 \mathrm{~nm}$ band-pass filter at $50 \mathrm{~mW} / \mathrm{cm}^{2}$ for $10 \mathrm{~min}$.

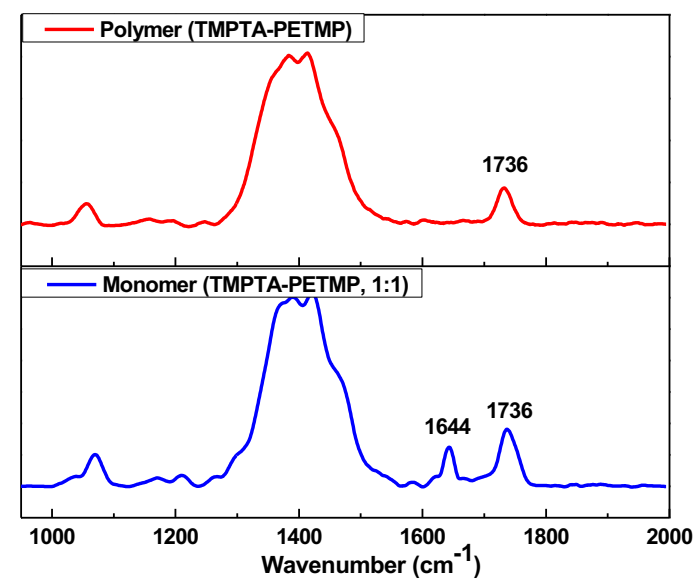

Fig S10. A comparison of Raman spectra of TMPTA-PETMP formulation before and after light exposure. Spectra of TMPTA-PETMP resin mixed in a 1:1 thiol:vinyl stoichiometric ratio in presence of $20 \mathrm{~mol} \%$ NPPOC-DEA and $1 \mathrm{~mol} \%$ Fmoc-TMG, before (blue) and after (red) irradiation at $50 \mathrm{~mW} / \mathrm{cm}^{2}$ for $10 \mathrm{~min}$. The reactive $\mathrm{C}=\mathrm{C}$ peak at 1644 $\mathrm{cm}^{-1}$ and an unchanging reference peak at $1736 \mathrm{~cm}^{-1}$ corresponding to $\mathrm{C}=\mathrm{O}$ carbonyl stretch were monitored to determine the acrylate conversion. 


\section{NMR}

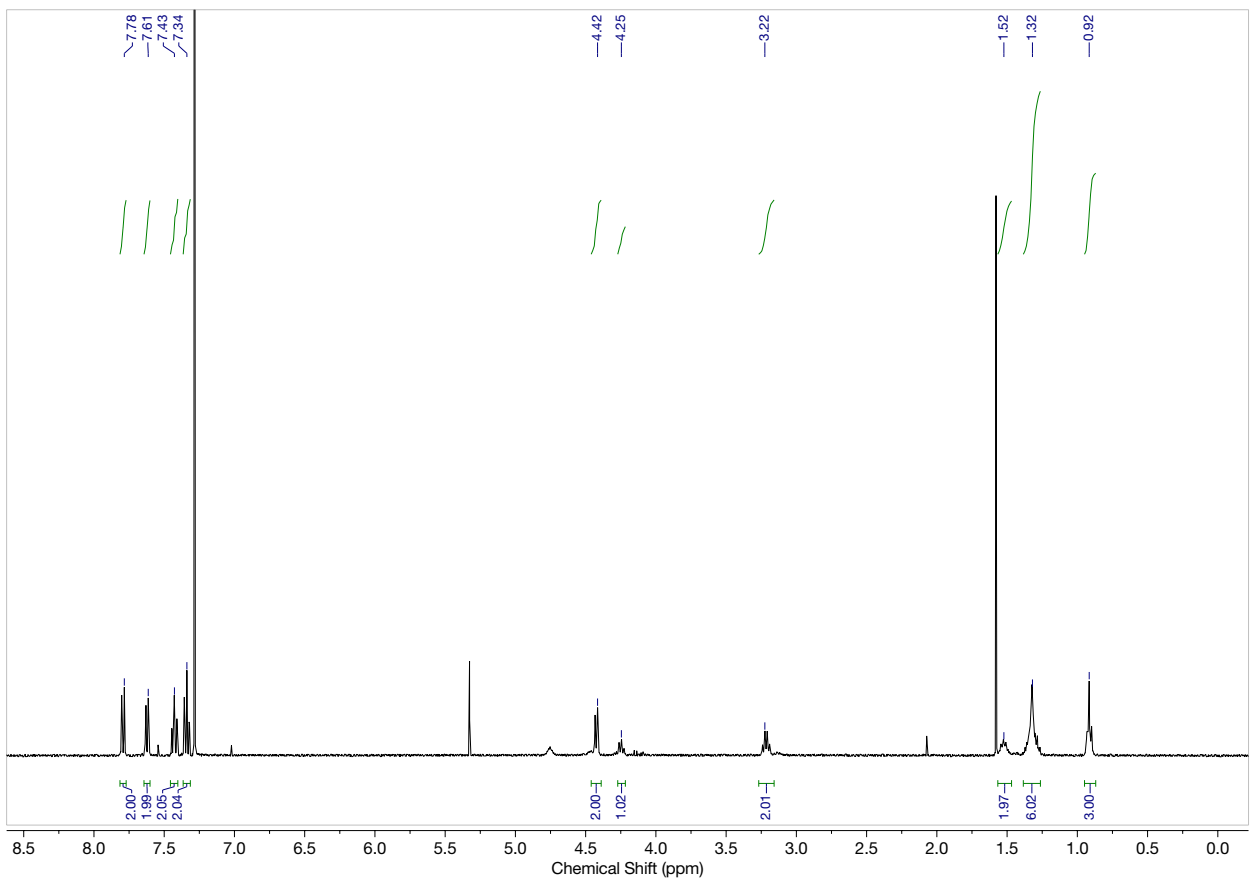

Fig S11. ${ }^{1} \mathrm{H}$ NMR of 1-(9-Fluorenylmethoxycarbonyl)-hexylamine (Fmoc-HEX).

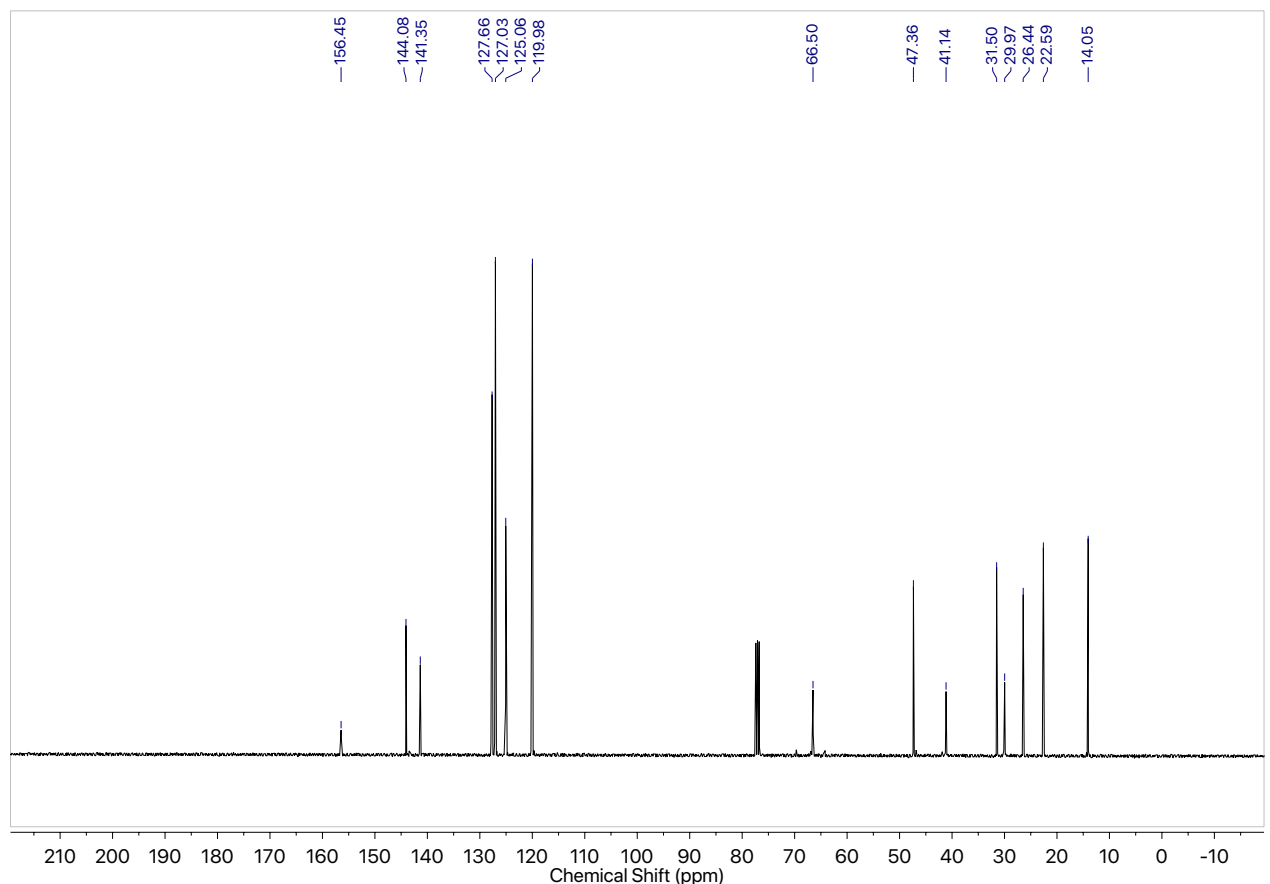

Fig S12. ${ }^{13}$ C NMR of 1-(9-Fluorenylmethoxycarbonyl)-hexylamine (Fmoc-HEX). 


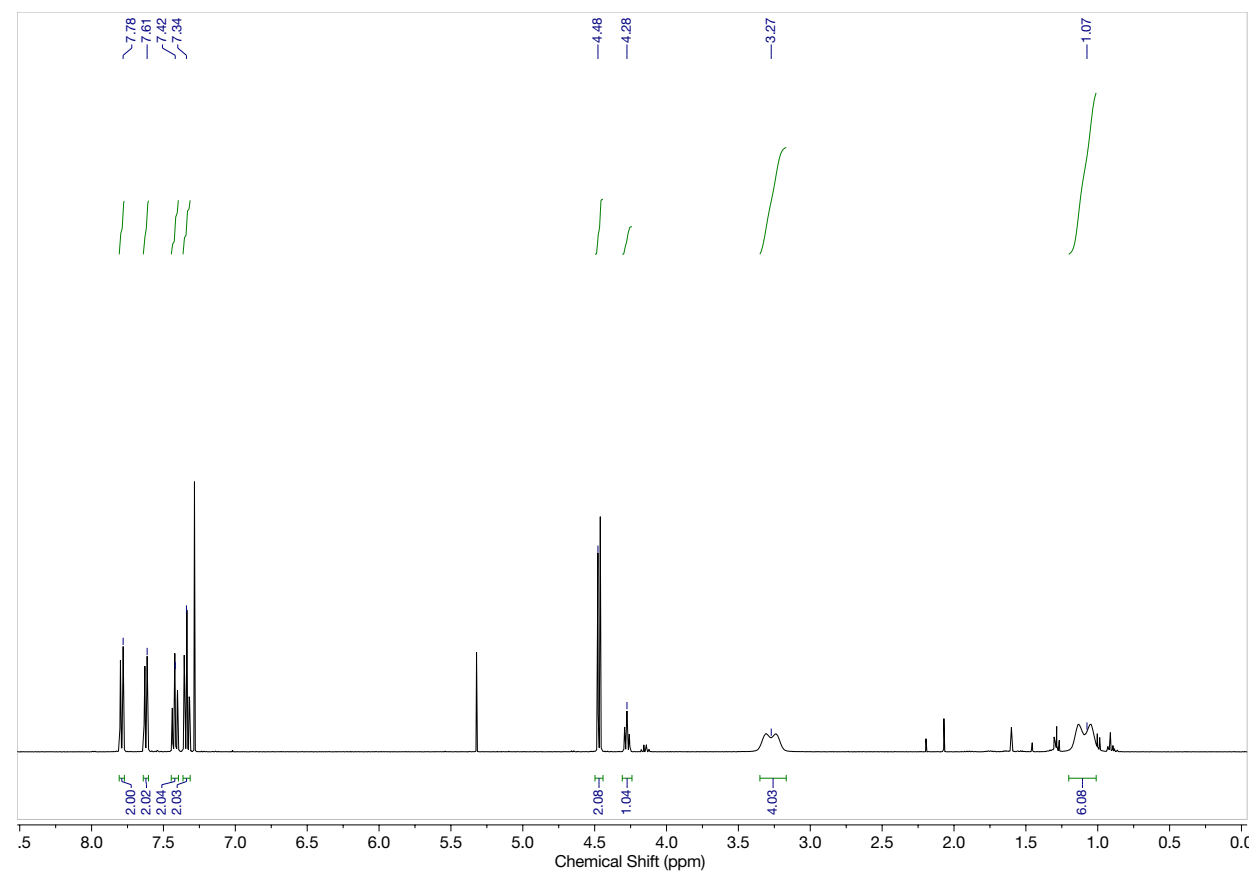

Fig S13. ${ }^{1} \mathrm{H}$ NMR of 1-(9-Fluorenylmethoxycarbonyl)-diethylamine (Fmoc-DEA).

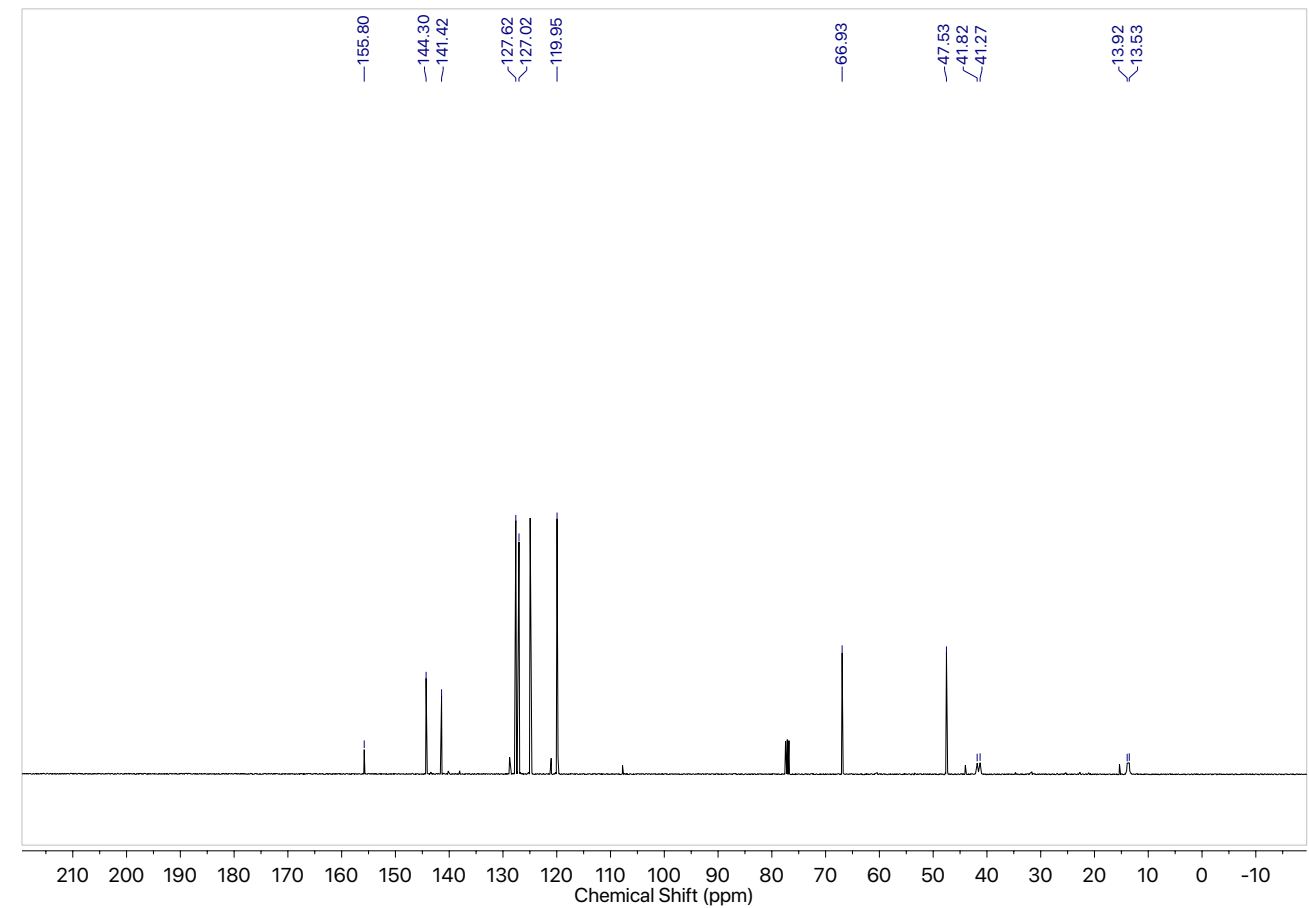

Fig S14. ${ }^{13} \mathrm{C}$ NMR of 1-(9-Fluorenylmethoxycarbonyl)-diethylamine (Fmoc-DEA). 


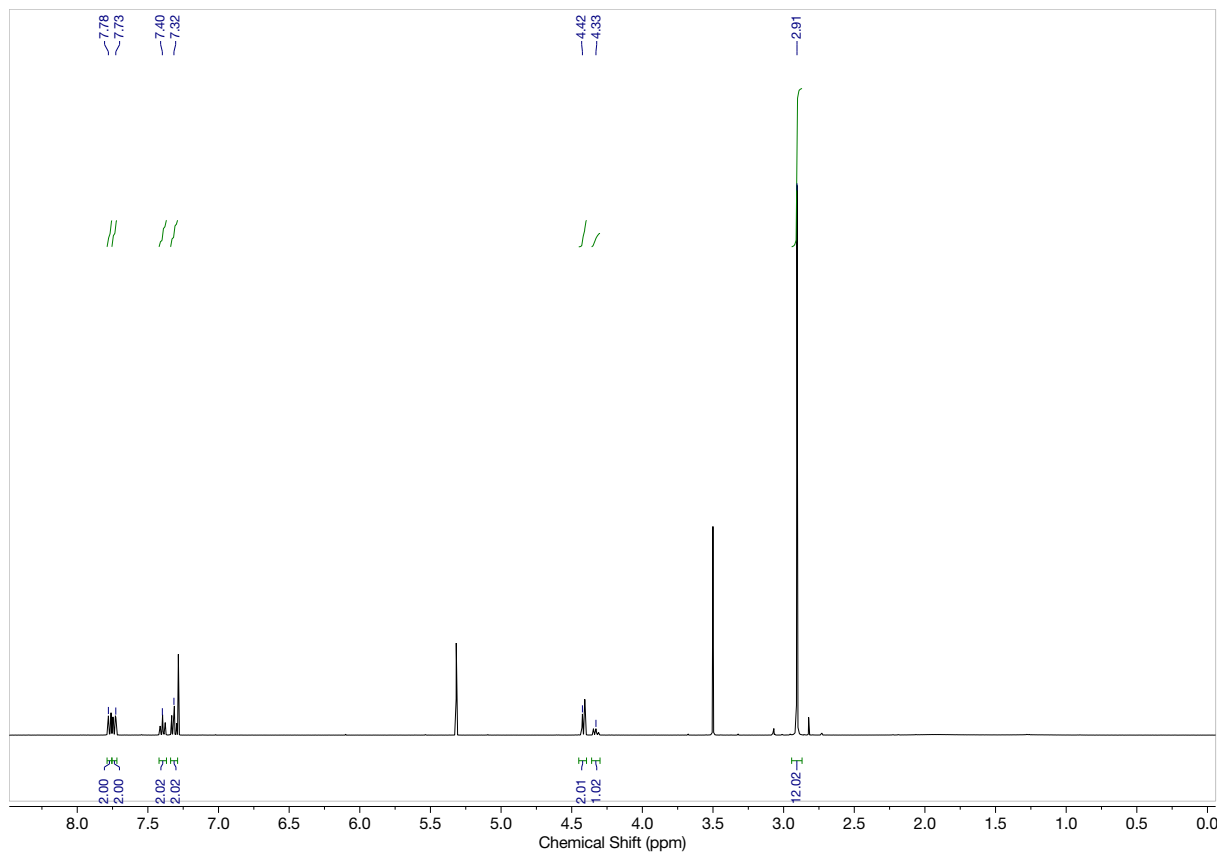

Fig S15. ${ }^{1} \mathrm{H}$ NMR of 1-(9-Fluorenylmethoxycarbonyl)- tetramethylguanidine (Fmoc-TMG).

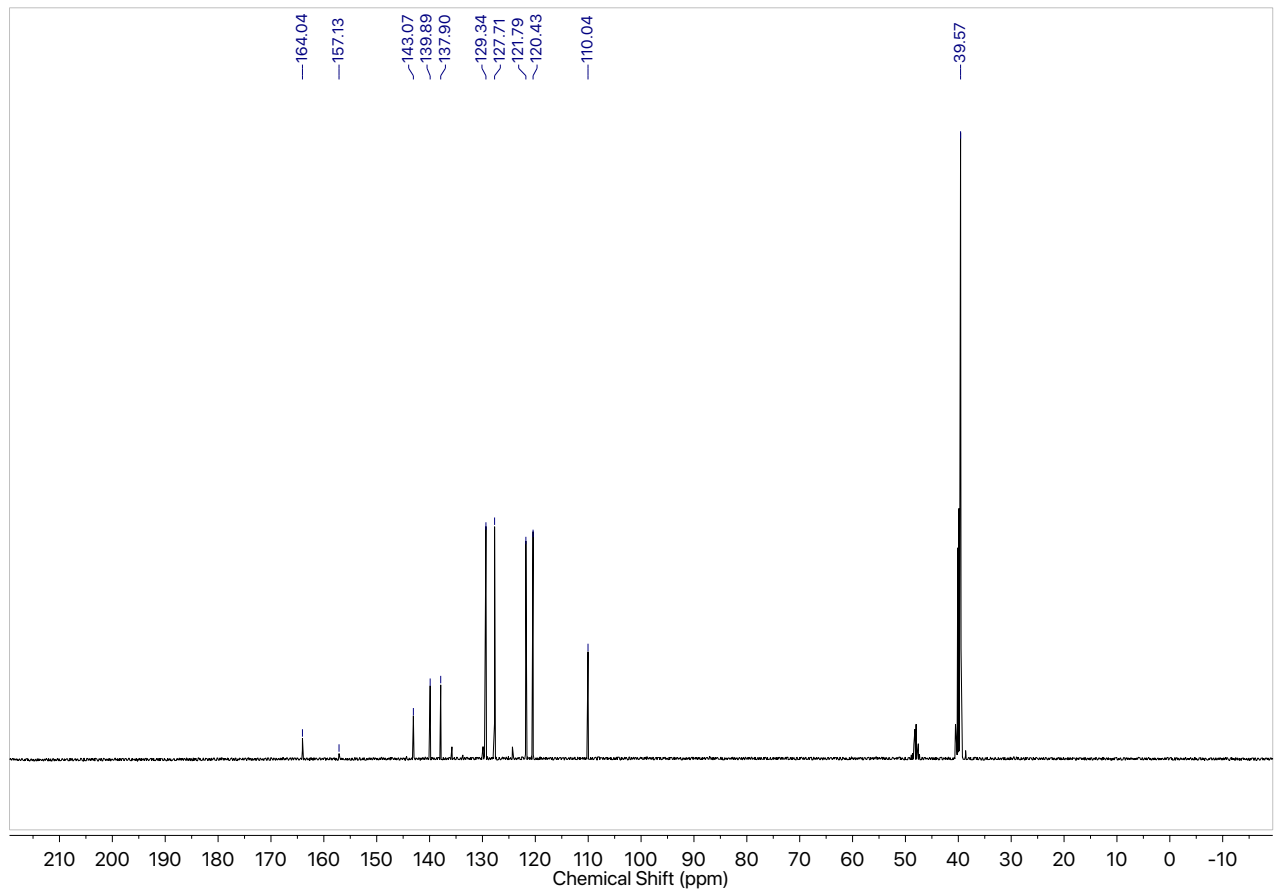

Fig S16. ${ }^{13} \mathrm{C}$ NMR of 1-(9-Fluorenylmethoxycarbonyl)- tetramethylguanidine (Fmoc-TMG). 


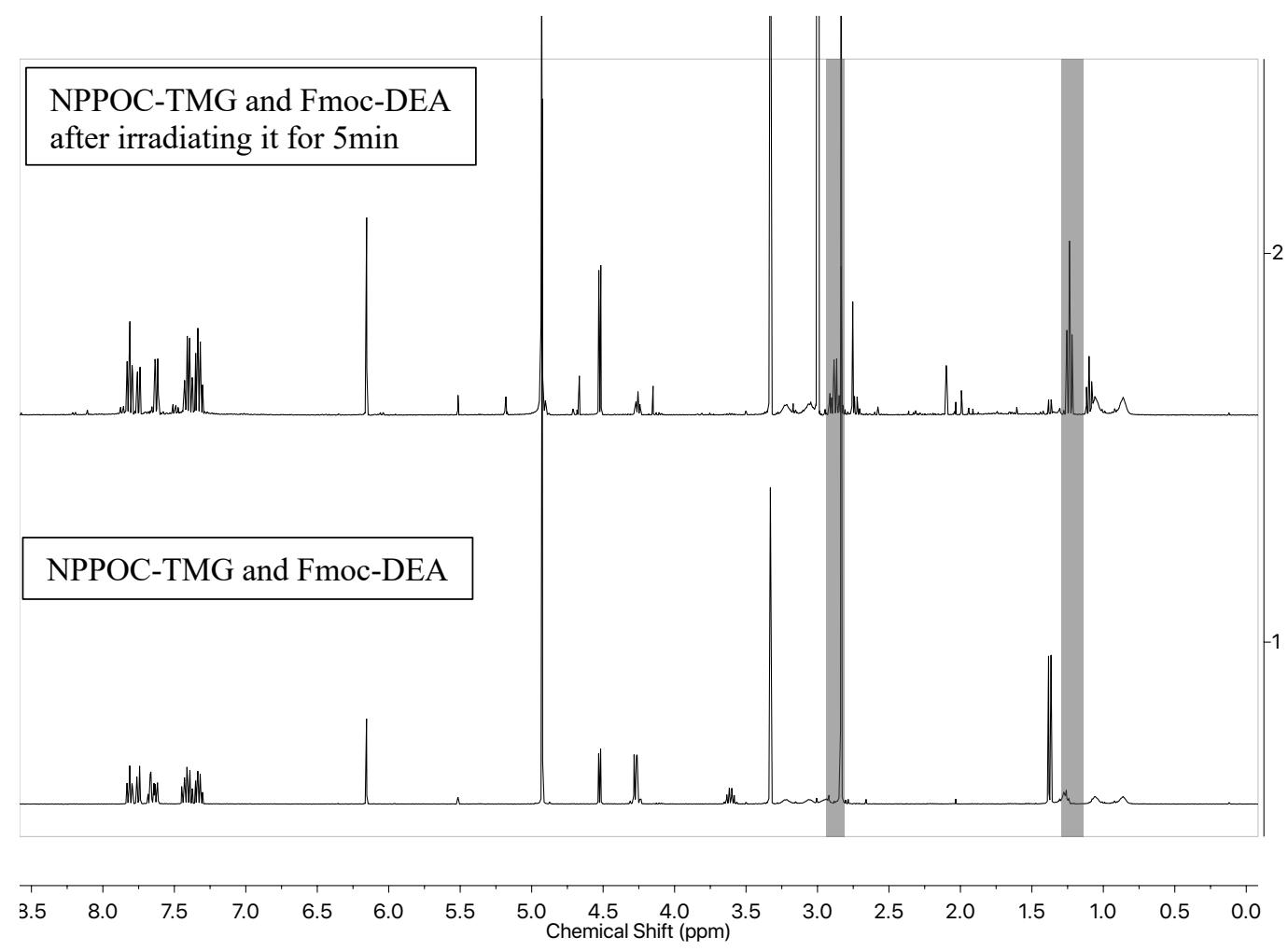

Fig S17. ${ }^{1} \mathrm{H}$ NMR of mixture of NPPOC-TMG and Fmoc-DEA (as control) and mixture of NPPOC-TMG and FmocDEA after irradiating it for $5 \mathrm{~min}$. 